\title{
Air pollution and other local factors in respiratory disease
}

\author{
A S Fairbairn, D D Reid
}

(This article originally appeared in the British fournal of Preventive and Social Medicine 1959;12:94-103. It was subsequently published in The epidemiological imagination. Ashton J ed. Buckingham: Open University Press, 1994 and is reprinted with permission)

The mortal risks of acute episodes such as the London smog of December 1952 are well recognised, but the insidious effects of lesser but more continuous atmospheric pollution are less clearly understood. Contrasts in bronchitic mortality between Great Britain and Scandinavia, and between town and country in the United Kingdom, strongly suggest that such effects are important. Uncovering the aetiology of a slowly progressive disease like chronic bronchitis involves the study of its evolution from trivial illness to ultimate death and its relation to other respiratory diseases. As a step towards this, we have used the sickness absence experience of British civil servants to supplement the usual mortality data available from the Registrar General's publications.

The British Civil Service offers considerable advantages as a population for epidemiological study. Numbering some 600000 , it has standard conditions of sick pay and superannuation and contains large groups, uniform in pay and job, widely distributed throughout the United Kingdom. The individual sickness absence records, giving the dates of onset and return to work and the certified diagnosis, are available for the whole of an employee's service and are afterwards retained for 10 years. They present a unique opportunity both for longitudinal studies of the natural history of disease and for the more usual cross-sectional study of current morbidity experience. The potential value of these data is evident in fig. 1 , which shows the distribution of the average time lost through sickness absence by postmen in different parts of the United Kingdom. This morbidity pattern again suggests the hazards to health of urban life which are so clearly implied by the urbanrural contrast in bronchitis mortality.

The limitations of such material must, however, be emphasised. Any occupational group is selected both by the individual's choice of career and by the employer's policy of recruitment and discharge. In the Civil Service such policy may vary between different occupations and at different periods. The effect of changes in retirement policy on sickness rates in the Post Office from 1891 to 1946 has been shown by Roberts (1948). Moreover, some illnesses may incapacitate, whether tem- porarily or permanently, those in arduous occupations but not those doing light indoor work. Sickness rates should thus be used with caution as measures of relative occupational risk or trends in morbidity. In ascribing importance to the different sickness rates of postmen and indoor workers, we have therefore looked for changes in difference with age, locality or diagnosis. No secular comparison of sick rates has been made. On the other hand, uniform medical standards of recruitment and ill-health retirement are applied by the Civil Service Commission and the Treasury Medical Service over the whole country, and comparisons by locality are largely free from bias due to staff selection as well as from that due to pay and job.

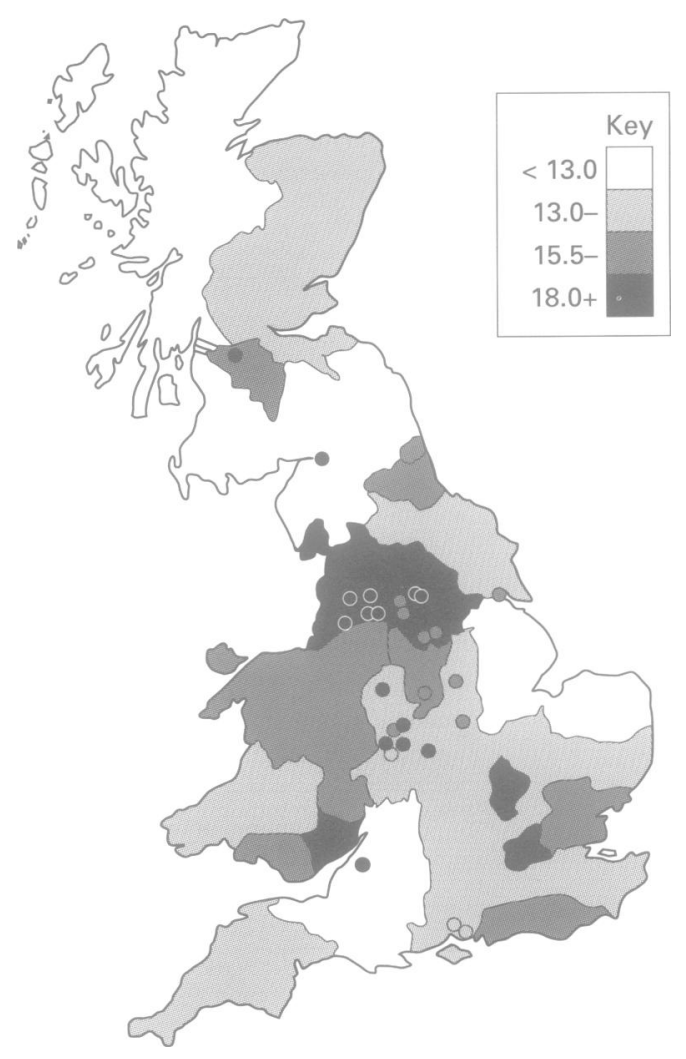

Figure 1 Average sick rate of postmen (days per manyear), 1947-1953, in the counties of England, Wales, and Scotland (large county boroughs shown separately). 
Table 1 Areas of United Kingdom ranked according to increasing values of fog index, in four groups approximately equal population

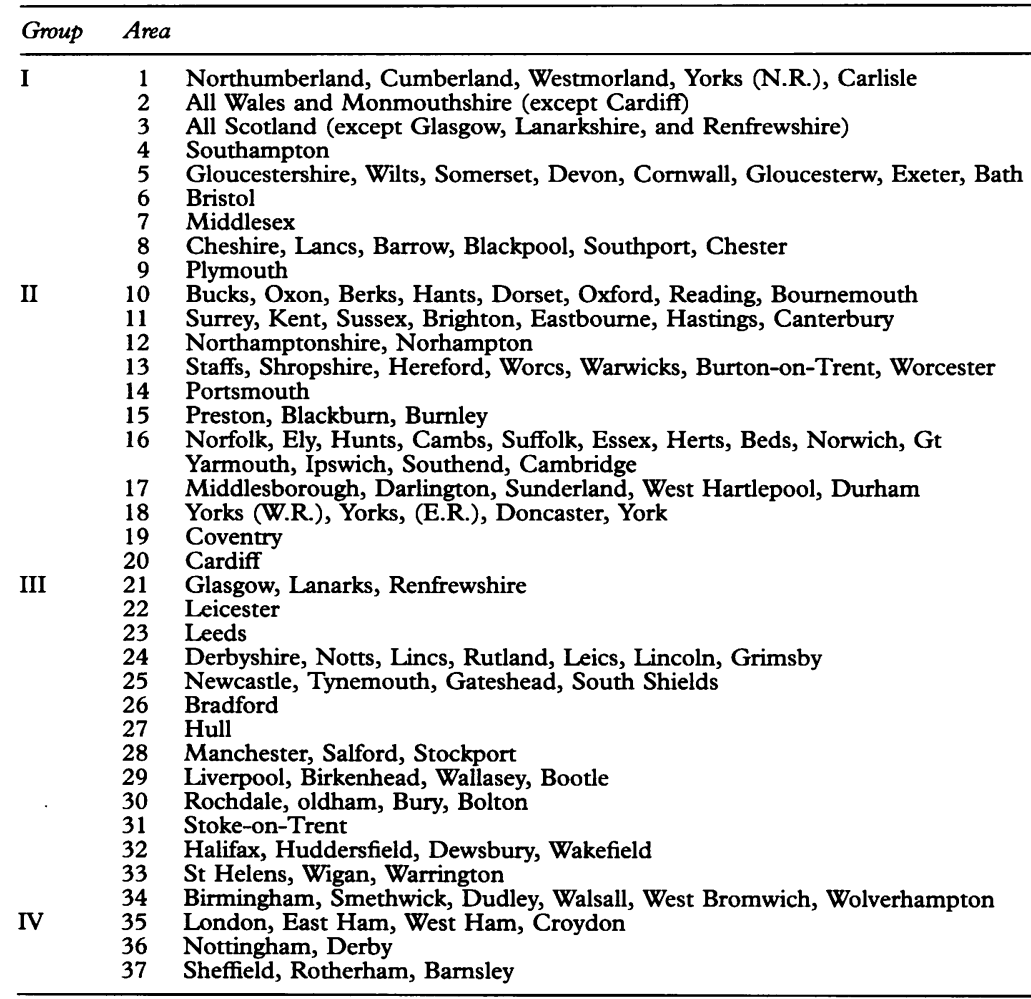

In this study respiratory mortality in the middle-aged population at large is first correlated with measures of air pollution, population density and domestic overcrowding, in different areas of the United Kingdom. Wastage and sickness rates among civil servants are then related to the same indices in the same areas. There follows a more detailed analysis of morbidity among the same civil servants at different ages and in areas with contrasting degrees of air pollution.

Fog index of presumptive air pollution While the acute effects of air pollution can be shown by time relationships, the study of its long-term effects usually depends on local contrasts in death and sickness in areas with different atmospheric conditions. Such comparisons have been hampered by the scarcity of stations for measuring air pollutants. Even now, these are largely confined to the more heavily polluted areas. Pemberton and Goldberg (1954), who correlated bronchitis mortality in the county boroughs of England and Wales with measurements of sulphur dioxide and smoke concentration, could obtain such data for only 37 of them. Daly (1954) calculated an index, based on fuel consumption, for all 83 county boroughs of England and Wales. Because our sickness absence data related to the whole country, we needed a still more comprehensive index, which we based on the results of a survey of visibility made in the winters of 1936-7 and 1937-8 (Durst, 1940). In this survey, about 1000 volunteers stationed in both town and country observed whether, at 9 am each morning, objects could be seen at a distance of
200 yards, 1100 yards or $11 / 4$ miles. For each station the index of visibility used was the percentage of occasions on which an object at 1100 yards was invisible. (The use of alternative ranges makes no material difference to the results.) For an area we took as an index the unweighted average of such frequencies.

Since the concentration of pollutants can increase without fog or smoke, visibility is only an indirect measure of atmospheric pollution. Unpolluted mist can occur; but this is mostly in the less populated hilly and coastal districts where it disperses quickly. These local exceptions have little effect on the values of the index for such grouped areas as were used in this study. Durst states that poor visibility is more closely associated with Tube air pollution in winter when these observations were made. The consistency of the index between the two years of the survey and its high correlation with recent measures of sulphur dioxide and with Daly's index of fuel consumption in areas where these were available warrant the assumption that the index is a useful guide to local levels of air pollution.

\section{Selection of areas}

The United Kingdom was divided into the 37 areas listed in table 1 , each consisting of one or more administrative In districts. Grouping was designed to avoid, as far as possible, sampling fluctuations due to a small Civil Service population or to scarcity of fog measuring stations. At the same time the aim was to combine only fairly homogeneous districts. Neighbouring administrative counties, for example, might form a rural area which excluded any large county borough within it. The more urban areas were generally single county boroughs or larger conurbations. On the other hand, the areas had to be large enough to correspond with the location code used to indicate the place of work in the Civil Service Staff Record. Areas such as Nos 2, 3 and 16 were thus unavoidably larger than would seem appropriate.

\section{Indices of population density and domestic overcrowding}

Respiratory disease is likely to be affected, independently of fog, by other urban characteristics. So that the effects of two of the major factors could be taken into account we calculated from the 1951 Census data indices for each area of population density and domestic overcrowding: the number of persons per acre and the percentage of persons living more than two to a room.

\section{Mortality study}

From the Annual Reviews of the Registrars General for England and Wales and Scotland, the number of deaths in the 37 areas for each sex at ages 45-64 from 1948 to 1954 have been extracted and related to the corresponding 1951 Census populations. The diagnostic categories include the main certified causes of 
Table 2 Detailed diagnostic categories used in mortality study

\begin{tabular}{ll}
\hline Diagnosis & $\begin{array}{l}\text { International List } \\
\text { code number }\end{array}$ \\
\hline Bronchitits & $500-502$ \\
Pneumonia & $490-493$ \\
Influenza & $480-483$ \\
Tuberculosis of respiratory system & $001-008$ \\
$\begin{array}{l}\text { Malignant neoplasm of trachea, } \\
\text { lung and bronchus }\end{array}$ & 162,163 \\
(England and Wales only) & \\
\hline
\end{tabular}

respiratory death: bronchitis, pneumonia, pulmonary tuberculosis, and cancer of the lung. Details of these are shown in table 2. Influenza was included, although the deaths are few, so that its pattern could be compared with that of sickness absence from the same certified cause.

The independent associations between the mortality rates and the indices of pollution, population density and domestic overcrowding have been expressed by second order productmoment correlation coefficients which allowed for variation in the other two factors. Any skew distributions were brought to approximate normality by transformations of the general type $\log (a+x)$, where the value of $a$ was chosen to bring the median of the distribution to the midpoint of the range (table 3 ).

The association of bronchitis mortality with the fog index in both sexes is highly significant; with population density and domestic overcrowding, it falls below the 5 per cent significance level.

Male pneumonia mortality is significantly correlated with fog and population density; for females, however, the coefficients, although ranked in the same order as for males, are not significantly high.

Because there are so few certified deaths, any relationship between influenza mortality and the other indices may be obscured; but the ranking of the coefficients is similar in both sexes and the correlations are greatest with fog.

Fog bears no direct relationship to pulmonary tuberculosis mortality, which shows a significant relationship in each sex to domestic overcrowding. Death in both sexes from pulmonary tuberculosis and cancer of the lung shows high associations with population density. Neither male nor female lung cancer death rates show any relation to fog or domestic overcrowding.

Table 3 Correlation of respiratory mortality at ages 45-64 with indices of air pollution, population density and domestic overcrowding in 37 areas of the United Kingdom

\begin{tabular}{lllll}
\hline Diagnosis & Sex & $\begin{array}{l}\text { Fog } \\
\text { index }\end{array}$ & $\begin{array}{l}\text { Persons } \\
\text { per acre }\end{array}$ & $\begin{array}{l}\text { Per cent persons more } \\
\text { than two per room }\end{array}$ \\
\hline Bronchitis & $\mathbf{M}$ & $+0.60^{\mathrm{b}}$ & +0.25 & +0.28 \\
Pneumonia & $\mathbf{F}$ & $+0.57^{\mathrm{b}}$ & +0.07 & +0.27 \\
& $\mathbf{M}$ & $+0.51^{\mathrm{b}}$ & $+0.46^{\mathrm{b}}$ & +0.15 \\
Influenza & $\mathbf{M}$ & +0.33 & +0.28 & +0.26 \\
& $\mathbf{F}$ & +0.23 & -0.01 & +0.06 \\
Pulmonary & $\mathbf{M}$ & +0.33 & -0.09 & +0.04 \\
tuberculosis & $\mathrm{F}$ & -0.02 & $+0.65^{\mathrm{b}}$ & $+0.49^{\mathrm{b}}$ \\
Cancer at the lung & $\mathbf{M}$ & +0.18 & $+0.48^{\mathrm{b}}$ & $+0.39^{\mathrm{a}}$ \\
& $\mathrm{F}$ & +0.23 & $+0.71^{\mathrm{b}}$ & +0.23 \\
& & $+0.59^{\mathrm{b}}$ & -0.03 \\
\hline
\end{tabular}

Product-moment correlation coefficients, allowing for variation in the other two factors. a Significant at 5 per cent level. ${ }^{\mathrm{b}}$ Significant at 1 per cent level. ${ }^{\mathrm{c}}$ England and Wales only (35 areas).
Table 4 Correlation of "total sickness" and "bronchitis wastage" rates in postmen with indices of air pollution, population density and domestic overcrowding in 37 ares of the United Kingdom

\begin{tabular}{llll}
\hline Rate & $\begin{array}{l}\text { Fog } \\
\text { index }\end{array}$ & $\begin{array}{l}\text { Persons } \\
\text { per acre }\end{array}$ & $\begin{array}{l}\text { Per cent persons more } \\
\text { than two per rom }\end{array}$ \\
\hline $\begin{array}{l}\text { Total sickness } \\
\text { Bronchitis }\end{array}$ & $+0.36^{\mathrm{a}}$ & $+0.39^{\mathrm{a}}$ & +0.13 \\
wastage & $+0.41^{\mathrm{a}}$ & -0.03 & +0.02 \\
\hline
\end{tabular}

Product-moment correlation coefficients, allowing for variation in the other two factors.

${ }^{2}$ Significant at 5 per cent level.

\section{Use of routinely collected Post Office} data

All 412 Postal Head Offices in the United Kingdom render an annual return showing the number of staff and the number of days lost through sickness absence in different grades. Through the kindness of the Deputy Treasury Medical Adviser, Dr M C W Long, and the Post Office authorities, we were provided with these data for the years 1948-54. These allowed the calculation of "total sickness" rates for postmen grouped according to their place of work. As in the Deputy Treasury Medical Adviser's Annual Report, these rates are expressed as the number of days lost per person per year. Dr Long also gave us access to Treasury Medical Service registers, from which were extracted particulars of all postmen dying in the service or prematurely retired between 1950 and 1954 because of bronchitis. By dividing the sum of deaths and retirements by the populations of postmen given in the annual returns, "bronchitis wastage" rates were de rived for each of the 37 areas. The age distribution of postmen hardly differed between areas, and the rates were not standardised for age. These "total sickness" and "bronchitis wastage" rates were correlated, in the same way as the mortality rates, with the same environmental indices. The results are shown in table 4.

The most serious index of bronchitic morbidity, given by the bronchitis wastage, is, like the mortality rate, significantly correlated only with fog. Total sickness shows significant associations with both fog and population density.

\section{Sample survey of Civil Service sickness absence}

More detailed information on age and diagnosis is available from a sample survey of sickness absence incurred in the Civil Service during 1946-53. The sickness records of all permanent civil servants born on the nineteenth day of any month who had served at any time during that period provided a quasi-random sample of about 3 per cent. For mechanical sorting, the particulars of each absence ending during the eight years (diagnosis, and dates of onset and return to work) were punched on a card, together with the officer's grade, age, place of work and other personal details.

To study differences between men doing indoor and outdoor work, and between men and women doing the same work, we took three large sections of the Civil Service: postmen, male clerical and executive staff, and 
Table 5 Sample survey of Civil Servant sickness absence: populations by age and occupational group (man-years)

\begin{tabular}{llll}
\hline $\begin{array}{l}\text { Age group } \\
\text { (years) }\end{array}$ & \multicolumn{3}{l}{ Occupational group } \\
\cline { 2 - 4 } & Postmen & Indoor males & Indoor females \\
\hline $15-24$ & 1530 & 2005 & 3208 \\
$25-34$ & 2336 & 7064 & 3361 \\
$35-44$ & 3017 & 4613 & 2446 \\
$45-54$ & 3987 & 8629 & 2030 \\
$55-59$ & 1394 & 4170 & 500 \\
\hline
\end{tabular}

Table 6 Sample survey of Civil Service absence: detailed diagnostic categories used in study of respiratory attack rates

\begin{tabular}{lll}
\hline & Diagnosis & International List code number \\
\hline 1 Lower respiratory group & Bronchitis & $500-502$ \\
& Pneumonia & $490-493$ \\
2 Upper respiratory group & Acute nasopharyngitis & 470 \\
(common cold) & Acute pharyngitis, tonsillitis, etc. & $472,472,510$ \\
& $\begin{array}{l}\text { Diseases of the ear and mastoid } \\
\text { process }\end{array}$ & $390-398$ \\
3 Influenza & & $480-483$ \\
\hline
\end{tabular}

Table 7 Sample survey of Civil Service sickness absence: correlation of respiratory attack rates in three occupational groups with indices of fog, population density and domestic overcrowding in 3 areas of the United Kingdom

\begin{tabular}{lllll}
\hline Diagnosis & $\begin{array}{l}\text { Occupational } \\
\text { group }\end{array}$ & $\begin{array}{l}\text { Fog } \\
\text { index }\end{array}$ & $\begin{array}{l}\text { Persons } \\
\text { per acre }\end{array}$ & $\begin{array}{l}\text { Per cent persons mone } \\
\text { than two per room }\end{array}$ \\
\hline Bronchitis and pneumonia & Postmen & +0.32 & +0.30 & +0.14 \\
& Indoor males & +0.29 & -0.15 & 0.00 \\
Colds, sore throats, etc & Indoor females & +0.36 & -0.18 & +0.10 \\
& Postmen & +0.24 & +0.05 & +0.10 \\
& Indoor males & -0.31 & +0.29 & -0.02 \\
Influenza & Indoor females & -0.24 & +0.28 & -0.29 \\
& Postmen & +0.12 & +0.26 & $+0.43^{\mathrm{a}}$ \\
& Indoor males & -0.32 & +0.21 & $+0.42^{\mathrm{a}}$ \\
& Indoor females & 0.00 & +0.18 & -0.12 \\
\hline
\end{tabular}

Product-moment correlation coefficients, allowing for variation in the other two factors. Significant at 5 per cent level.

Table 8 Sample survey of Civil Service sickness absence: local fog frequency and respiratory disease incidence

\begin{tabular}{llrrrr}
\hline Diagnosis & Occupational group & \multicolumn{2}{l}{ Fog group } & & \\
\cline { 3 - 6 } & & \multicolumn{1}{l}{$I$} & \multicolumn{1}{c}{$I I$} & \multicolumn{1}{c}{$I I$} & \multicolumn{1}{c}{$I V$} \\
\hline Bronchitis and pneumonia & Postmen & 40 & 53 & 115 & 122 \\
& Indoor males & 32 & 41 & 47 & 39 \\
& Indoor females & 37 & 49 & 51 & 52 \\
Colds, sore throats, etc & Postmen & 75 & 84 & 113 & 171 \\
& Indoor males & 53 & 51 & 63 & 64 \\
Influenza & Indoor females & 77 & 109 & 98 & 115 \\
& Postmen & 131 & 124 & 197 & 184 \\
& Indoor males & 88 & 81 & 90 & 102 \\
& Indoor females & 90 & 122 & 105 & 102 \\
\hline
\end{tabular}

Age-standardisation attack rates per 1000 man-years.

single female clerical and executive staff. For brevity the last two groups are referred to as "indoor males" and "indoor females". The total man-years of service for these populations available from the sample are shown in table 5 . Because of social factors affecting the absence pattern of married women, a better sex comparison is obtained by using the data for single women only. We have also excluded staff of 60 years old and over; because of the option of retirement at that age with immediate payment of pension, those who remain are a selected group.

For these three populations the sample survey provided attack rates averaged over the eight years for all absences certified as due to the main categories of respiratory illness. These categories, chosen to give rates based on reasonable numbers, are shown in table 6 . It may be noted that they differ from those of the mortality study. Diseases such as cancer of the lung and pulmonary tuberculosis cause few spells of sickness absence; conversely, very few deaths are certified as due to upper respiratory disease and comparatively few from influenza. Moreover, the same diagnosis which appears in certificates of both death and sickness absence may indicate illness that is different in kind as well as degree. Thus deaths from influenza are due chiefly to its pulmonary complications, while sickness absence generally relates to the uncomplicated initial illness.

In four areas, the sample populations were too small for analysis in this detail. Correlation coefficients were again calculated with the same indices but only in the remaining 33 areas. As in the case of postmen, age-standardisation was unnecessary for indoor males, but for indoor females we used a standardised of the observed attack rate in each area to that expected in the same population at total sample survey age-sex specific rates. The results are shown in table 7 .

Variability due to the rather small numbers of staff sampled in each may have reduced the number of significant results, and these respiratory attack rates are more usefully studied in the section that follows.

The only formally significant relationships are those of influenza with domestic overcrowding in both male populations. Despite this, the pattern of these coefficients can with advantage be compared with previous results. The association of bronchitis and pneumonia absence with fog approaches significance in all three populations, repeating at a lower level the significant relationship to fog of bronchitis wastage and death. Colds and sore throats present no features of interest.

\section{Analysis of morbidity sample data by age and presumptive air pollution}

For the more detailed analysis of morbidity in relation to air pollution, age, sex and job, the 37 areas were ranked according to the level of the fog index and divided into quartiles with nearly equal populations as shown in table 1 . Within each of the pollution groups of areas age-specific attack rates were calculated for the same diagnostic categories in each Civil Service population. To show the trend of sickness in relation to air pollution, age-standardised attack rates were calculated by averaging these age-specific rates within each pollution group. Conversely, averaging the age-specific rates over the four pollution groups gave the agetrend in morbidity after allowing for differences between these groups in their age structure.

Table 8 and figure 2 show the age-standardised attack rates for each diagnostic category plotted against the logarithm of the median fog index in each pollution group.

Table 9 and figure 3 show attack rates in the same populations, standardised for the fog index, in five age groups from 15 to 59 years. 
Bronchitis and pneumonia
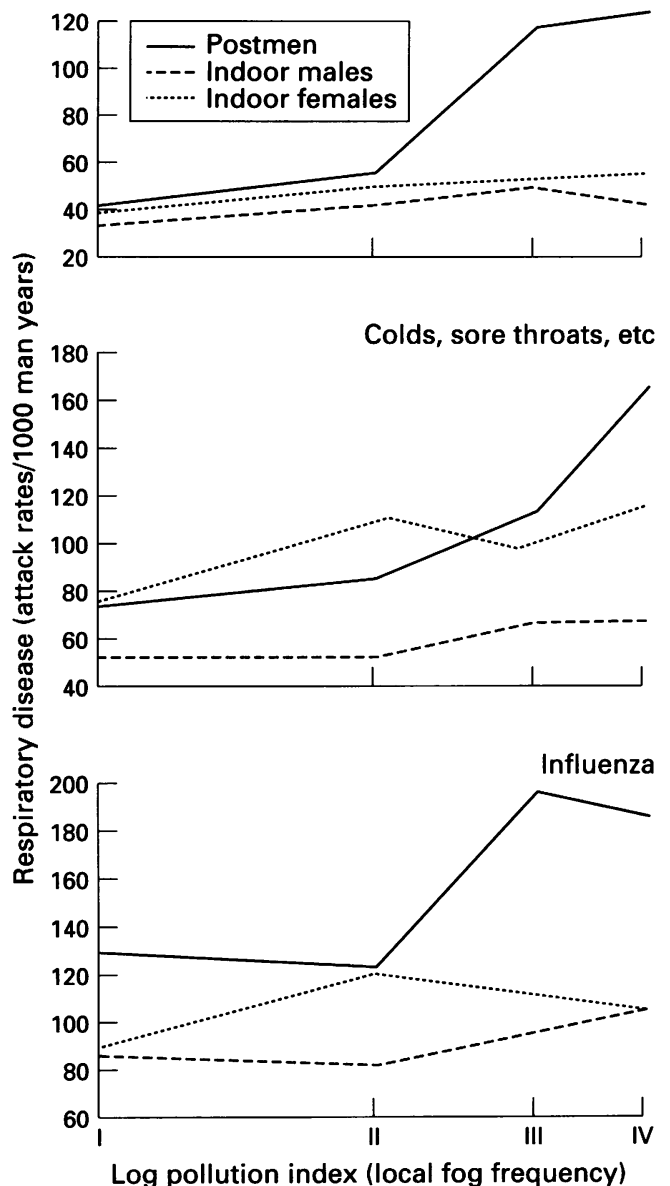

Figure 2 Local fog frequency and respiratory disease incidence by occupation.

Bronchitis and pneumonia attack rates in postmen and indoor males are closely similar in fog Groups I and 11; but there is a wide gap between the attack rates for postmen and indoor males in the more foggy districts. The attack rate for indoor males, unlike that for postmen, shows no rise with age until 35-44 years. It then rises in parallel with that for postmen. Indoor males thus have about the same attack rate as postmen 20 years younger. There is little difference between indoor males and females in any pollution or age group; the slight female excess in early life and male excess after age $\mathbf{4 5}$ is barely significant.

For colds, sore throats, etc. the rate for postmen diverges from that for indoor males with increasing pollution and the gap widens relatively

Table 9 Sample survey of Civil Service sickness absence: respiratory disease incidence by age

\begin{tabular}{llcrrrr}
\hline Diagnosis & Occupational group & \multicolumn{7}{l}{ Age group (years) } & & & \\
\cline { 3 - 7 } & & $15-24$ & $25-34$ & $35-44$ & $45-54$ & $55-59$ \\
\hline \multirow{2}{*}{ Bronchitis and pneumonia } & Postmen & 34 & 58 & 83 & 120 & 154 \\
& Indoor males & 24 & 18 & 33 & 67 & 76 \\
Colds, sore throats, etc & Indoor females & 30 & 33 & 42 & 74 & 65 \\
& Postmen & 143 & 138 & 110 & 79 & 56 \\
& Indoor males & 69 & 61 & 57 & 51 & 45 \\
Influenza & Indoor females & 164 & 104 & 74 & 73 & 65 \\
& Postmen & 126 & 193 & 176 & 147 & 149 \\
& Indoor males & 71 & 85 & 103 & 98 & 99 \\
& Indoor females & 118 & 83 & 108 & 124 & 78 \\
\hline
\end{tabular}

Attack rates per 1000 man-years standardised for local fog frequency.

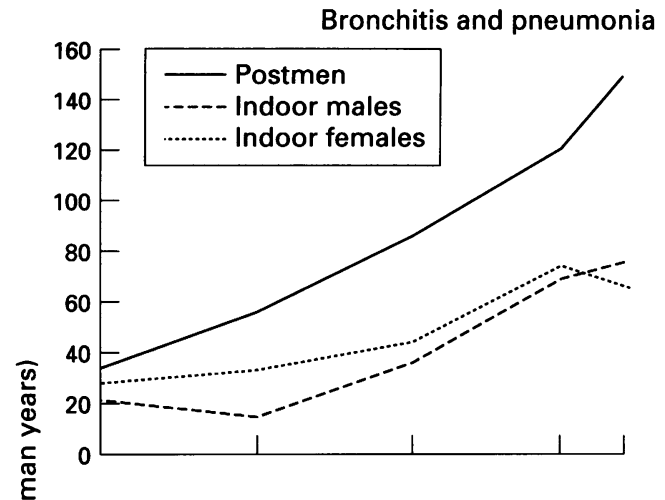

\section{Discussion}

The prime interest in this study lay in the effects of air pollution and other features of urban life on respiratory disease and mortality. The interpretation of the results largely depends on the consistency of the patterns observed. From each source of data has come evidence on the relevance of air pollution to respiratory disease. Severe chronic bronchitis, causing disablement or death among postmen or death among middle-aged men and women 
in different parts of the country, is, for example, specifically related to the frequency of winter fog in the same areas. Pneumonia mortality among males is significantly and independently associated with fog frequency as well as with population density. The death rates in both sexes from influenza, so commonly lethal in bronchitics, are associated, although not significantly, with fog rather than with the other local indices. Sickness absences from bronchitis and pneumonia among all grades of staff also bear a consistent, though not a technically significant, relation to fog. Among postmen working out of doors in areas of high presumptive air pollution, the bronchitis and pneumonia absence rate is much higher than among male indoor staff. Colds and sore throats show the same selective incidence in postmen in these more polluted areas. The steady rise with age in the bronchitic absence rate among postmen contrasts with an increase in male indoor workers which occurs only after the age of 45 . The complementary age trends in upper and lower respiratory disease, which suggest more frequent chest complications with advancing age, are especially marked among postmen. All these findings are consistent with a specific effect on outdoor staff of exposure to fog and, presumably, to air pollution. This seems reasonable, for not only may outdoor levels of pollution be greater but the physical demands of the postman's round increase the amount of such air inhaled. Early duty may also expose him to morning peaks in the concentration of pollutants (Department of Scientific and Industrial Research, 1955).

On the other hand, the independent relation of these rates to population density may well result from variation in morale and sickness absence in general with the size of the working group (Acton Society Trust, 1953). Morale may be better in the small rural offices where the contact between management and staff can be more personal. Similarly, a peak at the menopausal age in all female sickness absence rates is of a general nature and not restricted to any particular diagnostic category.

An urban excess in respiratory disease could be due to increased opportunities for infective contact. The higher influenza attack rates among male staff in areas with much domestic overcrowding, like the corresponding death rates from pulmonary tuberculosis, emphasise the importance of cross-infection in respiratory morbidity. The absence of such a correlation among single female staff may be explained by the lesser risk of their contact with infection from school children in the home.

Increased opportunities for cross-infection outside the home might be suggested by the correlation between population density and mortality from pulmonary tuberculosis and pneumonia. On the other hand, the corresponding correlation for cancer of the lung can hardly have the same basis. Neither pulmonary tuberculosis nor lung cancer is directly related to local fog frequency. No support is therefore given to the suggestion of Stocks and Campbell (1955) that air pollution contributes appreciably to the genesis of lung cancer. Lowe
(1956) found that the notification rate for pulmonary tuberculosis among older subjects of both sexes was related to smoking frequency, which suggests that this is the urban factor common to middle-age mortality both from this disease and from cancer of the lung. Although, according to a recent report, the current urbanrural gradient in cigarette smoking is small (Todd, 1957), it may have been greater in previous decades.

Smoking could also explain the relationship between male pneumonia mortality and population density, particularly in view of the possible diagnostic confusion with lung cancer. No evidence on the effect of smoking on the incidence of bronchitis emerges from this study. The urban-rural gradient in bronchitic mortality or serious morbidity can be explained by local variations in fog frequency. The excess of bronchitic morbidity in indoor male staff over 45 years of age compared with their female colleagues, which might be attributable to smoking (Oswald and Medvei, 1955), is small, though consistent with previous findings (Reid, 1956; Higgins, 1957) and with the excessive male mortality in later life. But without further information, the relevance of smoking to bronchitis in the occupational groups surveyed cannot be assessed.

\section{Summary}

Respiratory sickness and death rates obtained from various sources have been related to indices of air pollution and other urban characteristics in different areas of the United Kingdom.

Sickness absence data, derived from a survey among civil servants, allowed comparisons between outdoor postmen and indoor male office workers, and between men and women doing the same work in the same indoor environment. Attack rates from four major types of respiratory illness have been calculated in these groups for 37 urban and rural areas of the United Kingdom. From routinely collected data on the experience of postmen, the rates for death and permanent disablement from chronic bronchitis and the total time lost through sickness have been calculated for the same areas.

These Civil Service data have been collated with death rates from bronchitis, pneumonia, pulmonary tuberculosis, cancer of the lung and influenza among the general middle-aged population (45-64 years) of both sexes in these 37 areas over the same period. Both mortality and morbidity rates have been correlated with three indices of local environment: frequency of fog, number of persons per acre and percentage of persons living more than two to a room.

The trends with age and with fog frequency in the respiratory attack rates have also been examined.

Analysis of the material suggests that, apart from general influences affecting sickness absence, such as group morale or the "menopausal peak", environmental factors influence the distribution of respiratory disease in the 
populations surveyed. Severe bronchitis causing permanent disablement and death among postmen exposed by their job to atmospheric conditions is uniquely related to the frequency of fog, and, presumably, to the level of air pollution. These rates in a group whose job and pay are uniform throughout the country run parallel to local bronchitis death rates in middle age. Variations in the latter are not related to population density or to domestic overcrowding, and may thus result from a specific effect of air pollution on respiratory disease.

The high incidence of influenza morbidity and tuberculosis mortality in areas with much domestic overcrowding emphasises the importance of cross-infection in the home. Some of the excessive urban mortality from pulmonary tuberculosis and pneumonia may also be due to increased opportunities for infection; but the singular association of lung cancer mortality with population density and not with the fog index of air pollution suggests that urban-rural differences in smoking habits may have affected the risk of death from three major causes of respiratory mortality: lung cancer, pulmonary tuberculosis and, perhaps, pneumonia. The relevance of smoking habits to bronchitis could not be assessed from the available data.

Acton Society Trust. Size and Morale. 1953.

Daly C. Brit Med $₹$ 1954;2:687.

Department of Scientific and Industrial Research. The Investigation of Atmospheric Pollution 1955.

Durst CS. Winter Fog and Mist Investigations in the British Isles 1930-7. Met Office Mem.

Higgins IT. Brit Med $\mathcal{f}$ 1957;2:1198.

Lowe CR. Ibid. 1956;2:1081.

Oswald NE, Medvei VC. Lancet 1955;2:843

Pemberton J, Goldberg C. Brit Med f 1954;2:567.

Reid D. Proc Roy Soc Med 1956;49:767.

Roberts C. Monthly Bull Minist Hlth 1948;7:189.

Stocks P, Campbell JM. Brit Med f 1955;2:923.

Todd GF. Tobacco Manufacturers' Standing Committee Research Papers. No 1: Statistics of Smoking 1957.

Fairbairn AS, Reid DD. Air pollution and other local factors in respiratory disease. Br $\mathfrak{f}$ Prev Soc Med 1958;12:94-103. 